\title{
Pilose antler peptide promotes osteoblast proliferation, differentiation and mineralization via the insulin signaling pathway
}

\author{
CHANGJUN YUN ${ }^{1,2}$, WENJIE QIAN ${ }^{1,2}$, JUNYI WU $^{1,2}$, CHENXI YUAN $^{1,2}$, \\ SONGZHOU JIANG ${ }^{3}$ and JINPENG LV ${ }^{1-3}$ \\ ${ }^{1}$ Department of Orthopedics, Wujin Hospital Affiliated with Jiangsu University; \\ ${ }^{2}$ The Wujin Clinical College of Xuzhou Medical University; ${ }^{3}$ College of \\ Pharmaceutical Engineering and Life Sciences, Changzhou University, \\ Changzhou, Jiangsu 213000, P.R. China
}

Received April 27, 2019; Accepted November 15, 2019

DOI: $10.3892 /$ etm.2019.8286

\begin{abstract}
Osteoporosis is a severe bone disease characterized by a decrease in the density and structure of bones, with high risks of fractures. Pilose antler peptide (PAP), extracted and purified from deer antlers, can promote regeneration and fracture healing, and strengthen sinews and bone. To determine whether PAP can promote osteoblast development and to elucidate the molecular mechanisms underlying its functions, the present study investigated the effects of PAP on osteoblast proliferation, differentiation and mineralization, and the role of the insulin signaling pathway using MTT assay, alkaline phosphatase activity assay, western blot analysis and reverse transcription-quantitative PCR. The present results suggested that PAP promoted osteoblast proliferation, differentiation and mineralization in vitro via the insulin signaling pathway. The effect of PAP on insulin signaling in osteoblasts may be mediated via the ERK pathway and partially by the PI3K/Akt pathway. The present results indicated that PAP could potentially be developed as an alternative treatment strategy for bone diseases related to diabetes characterized by insulin signaling impairment.
\end{abstract}

Correspondence to: Dr Changjun Yun, Department of Orthopedics, Wujin Hospital Affiliated with Jiangsu University, 2 Yongning North Road, Changzhou, Jiangsu 213000, P.R. China E-mail: yunchangjun@sina.com

Dr Jinpeng Lv, College of Pharmaceutical Engineering and Life Sciences, Changzhou University, 1 Gehu Road, Changzhou, Jiangsu 213000, P.R. China

E-mail: lvjinpeng1988@126.com

Key words: pilose antler peptide, osteoblast, insulin signaling pathway

\section{Introduction}

Osteoporosis is a major health concern characterized by a decrease in the density and quality of bones, with high risks of bone fractures (1). Worldwide, osteoporosis causes $>8.9$ million fractures annually, resulting in an osteoporotic fracture every $3 \mathrm{sec}$ (1). In China, osteoporosis affects $\sim 70$ million individuals aged $\geq 50$, and causes $\sim 687,000$ hip fractures annually (2). The overall prevalence of osteoporosis in mainland China is $7 \%$ among adults; $22.5 \%$ among males and $50.1 \%$ among females aged $\geq 50$ years ( 3 ).

The imbalance between the function of osteoblasts and osteoclasts contributes to bone disease (4). Osteoblast maturation is a multistep series of events, including proliferation, differentiation and mineralization, which are modulated by the interactions of a variety of cytokines and signaling pathways (4). Since the discovery of insulin receptor in osteoblasts (5), the role of insulin signaling in bone has attracted increasing attention. Previous studies have confirmed that insulin signaling is essential for osteoblast function (5). Mice lacking insulin receptors in osteoblasts have been shown to develop postnatal osteopenia, and IR-deficient osteoblasts in vitro have been shown to have a lower proliferative and differentiation capacity (6). Moreover, direct treatment with insulin promotes osteoblast proliferation, differentiation and collagen synthesis $(7,8)$. After insulin binds to its receptor, the insulin receptor substrate (IRS) family acts as docking proteins between insulin receptors and intracellular signaling molecules (7). There are four subtype members of the IRS family, IRS-1, IRS-2, IRS-3 and IRS-4, but only IRS-1 and IRS-2 play important roles in bone development via insulin signal transduction $(9,10)$. Specifically, genetically modified mice lacking the IRS-1 or IRS-2 gene exhibit severe osteopenia with a low bone turnover, and cultured IRS-1 $1^{-/}$and IRS-2 ${ }^{-/}$osteoblasts exhibit reduced proliferation, differentiation and matrix synthesis (10). Furthermore, a previous in vitro study that suppressed the expression of IRS-1 and IRS-2 in L6 myotubes using small interfering RNA, revealed IRS-1 more closely regulated glucose uptake and IRS-2 seemed to 
be more closely linked to mitogen-activated protein kinase (MAPK) activation (11). The two main downstream intracellular components of the insulin signaling pathway include MAPK, which is mainly responsible for cell proliferation and differentiation, and PI3K/Akt, primarily regulating metabolic function (12). While the MAPK and PI3K/Akt signaling pathways play different roles in insulin functions, both can control cell growth and differentiation (12).

Pilose antler peptide (PAP; molecular weight, 7,200; amino acid residue, 68) is extracted and purified from deer antlers, and is a well-known Chinese traditional medicine identified to exert beneficial effects against inflammation and oxidative injury $(13,14)$. Previous studies have shown that PAP can protect a number of organs, including the brain, lungs and liver, from inflammation and oxidative stress (15-18). However, to the best of our knowledge, only a few studies have focused on the effects of PAP on bone function, and on the underlying molecular mechanisms related to the NF- $\kappa$ B pathway, the classical pathway of inflammation $(19,20)$.

Considering the effects of PAP and the roles of the insulin signaling pathway in osteoblasts, the present study hypothesized that PAP may promote osteoblast development in a dose-dependent manner, and that this may be related to insulin signaling. To investigate this, MTT assay, alkaline phosphatase (ALP) activity assay, western blot analysis and reverse transcription-quantitative PCR (RT-qPCR) for osteogenesis-related markers and downstream insulin signaling pathway markers were performed.

\section{Materials and methods}

Reagents. PAP was purchased from Shanghai Ai Shuang Commerce Co., Ltd. and dissolved in DMSO. The final concentration of DMSO was $<0.1 \%(\mathrm{v} / \mathrm{v})$. The MC3T3-E1 osteoblastic cell subclone 4 cell line (cat. no. CRL-2593; pre-osteoblast; mouse C57BL/6 calvaria) was purchased from the American Type Culture Collection. The BCIP/NBT alkaline phosphatase (ALP) staining kit (SBJ-1049) and Mineralized nodule staining solution of osteoblasts (Alizarin Red S staining kit, SBJ-1711) were purchased from SenBeiJia Biological Technology Co. Ltd. PrimeScript ${ }^{\mathrm{TM}}$ RT Master Mix kits (RR036A) were purchased from Takara Biomedical Technology Co. Ltd.

Cell culture. The MC3T3-E1 osteoblastic cell subclone 4 cell line was cultured in AA-free $\alpha$-modified Eagle's medium ( $\alpha$-MEM; cat. no. 11900024; Gibco; Thermo Fisher Scientific, Inc.) containing 10\% FBS (Gibco; Thermo Fisher Scientific, Inc.), $100 \mu / \mathrm{ml}$ penicillin and $100 \mu \mathrm{g} / \mathrm{ml}$ streptomycin at $37^{\circ} \mathrm{C}$ in a humidified atmosphere with $5 \% \mathrm{CO}_{2}$ for 7 days.

MC3T3-E1 cell differentiation and mineralization. MC3T3-E1 cells at a density of $2 \times 10^{6}$ cells $/ \mathrm{ml}$ for 7 days or $1 \times 10^{6}$ cells $/ \mathrm{ml}$ for 14 days were seeded in a 6 -well plate. All samples were performed in triplicate. After the cells reached $80 \%$ confluence, the medium was replaced with $\alpha$-MEM containing $5 \mathrm{mM} \beta$-glycerophosphate and $500 \mu \mathrm{M}$ ascorbic acid to facilitate in vitro mineralization. Cells were treated with various concentrations of PAP $(0,25,50$ and $100 \mathrm{mg} / \mathrm{l})$ at $37^{\circ} \mathrm{C}$ in a humidified atmosphere with $5 \% \mathrm{CO}_{2}$ for 3,7 or 14 days. The cells were harvested for cell differentiation, mineralization and related assays. In some experiments, the ERK inhibitor PD98059 (PD) and the PI3K inhibitor LY294002 (LY) were added in advance for $1 \mathrm{~h}$ at $37^{\circ} \mathrm{C}$ before and during exposure to PAP.

Cell viability and proliferation assay. Cell viability and proliferation were assessed by MTT assay. Cells were seeded at $1 \times 10^{5}$ cells $/ \mathrm{ml}$ in $96-w e l l$ plates. Following $24 \mathrm{~h}$ of incubation at $37^{\circ} \mathrm{C}$, the culture medium was replaced with $\alpha$-MEM containing 2.5\% FBS (Gibco; Thermo Fisher Scientific, Inc.) and the cells were treated with PAP $(0,25,50$ and $100 \mathrm{mg} / \mathrm{l})$ for $1,3,5$ and 7 days. Cell viability assay was performed after 1 day and cell proliferation assay was conducted on the indicated days. MTT assay was performed as previously described (21). Cells were washed with PBS three times, and $20 \mu 15 \mathrm{mg} / \mathrm{ml}$ MTT was added to each well followed by incubation for $4 \mathrm{~h}$ at $37^{\circ} \mathrm{C}$. Following solution removal, $200 \mu \mathrm{l}$ of DMSO was added to each well to dissolve the purple formazan. The resultant absorbance was measured with plate reader at a $490 \mathrm{~nm}$ test wavelength, using a reference wavelength of $650 \mathrm{~nm}$.

ALP staining and activity analysis. ALP staining was performed according to the manufacturer's instructions provided with the BCIP/NBT kit (SenBeiJia Biological Technology Co. Ltd). Cells treated with PAP for 7 days were rinsed with PBS multiple times and fixed with $4 \%$ paraformaldehyde for $30 \mathrm{~min}$ at $4^{\circ} \mathrm{C}$. The fixed samples $(6 \mu \mathrm{m})$ were covered completely with BCIP/NBT working solution for $60 \mathrm{~min}$ in the dark at room temperature. Finally, the cells were washed with PBS 2-3 times and images (x200) were acquired using a light microscope (IX73, Olympus Corporation).

ALP activity was assayed by the p-Nitrophenyl Phosphate (PNPP) assay. Protein samples were collected and quantified using the BCA kit (cat. no. P0012, Beyotime Institute of Biotechnology). This was followed by the incubation of $20 \mu \mathrm{l}$ of protein supernatant with $100 \mu 1$ PNPP solution in a 96-well plate for $15 \mathrm{~min}$ at $37^{\circ} \mathrm{C}$. All samples were performed in triplicate. The absorbance values were recorded at $405 \mathrm{~nm}$ and ALP activity was determined by optical density (OD) value per $\mathrm{mg}$ of total protein.

Alizarin Red S staining. After 14 days, the cells in 6-well plates were treated with Alizarin Red S staining solution to visualize bone nodule formation. The cells were washed twice with PBS and fixed with $4 \%$ paraformaldehyde for $30 \mathrm{~min}$ at room temperature, then rinsed twice with double-distilled $\mathrm{H}_{2} \mathrm{O}$. The fixed cells were then stained with $0.5 \%$ Alizarin Red S (pH 4.2) for $30 \mathrm{~min}$ at room temperature with gentle shaking. Finally, the cells were washed with PBS 2-3 times and images (x200) were acquired using a light microscope (IX73, Olympus Corporation). The quantification of Alizarin Red S staining was determined by the addition of a solution of $20 \%$ methanol and $10 \%$ acetic acid. The optical density was measured at an absorbance of $450 \mathrm{~nm}$.

Western blot analysis. The protein suspension of cells was obtained using a cell lysis buffer for Western and IP kit (cat. no. P0013; Beyotime Institute of Biotechnology) and the protein concentrations were determined by BCA Protein Assay kit (cat. no. P0011; Beyotime Institute of Biotechnology). For 
each of the samples, the extracted total proteins $(40 \mu \mathrm{g})$ were separated on $10 \%$ SDS-PAGE gels and then transferred onto a nitrocellulose filter membrane using an electrophoretic transfer system (Bio-Rad Laboratories, Inc.). The membranes were blocked for $1.5 \mathrm{~h}$ at room temperature with $2.5 \% \mathrm{BSA}$ in TBST and then incubated with the following Abcam supplied antibodies: Anti- $\beta$-actin (1:3,000; cat. no. ab8224), anti-insulin receptor (1:2,000; cat. no. ab137747), anti-IRS-1 (1:1,000; cat. no. ab52167), anti-IRS-2 (1:2,000; cat. no. ab134101), anti-phosphorylated-InsR (1:1,000; cat. no. ab60946), anti-phospho-IRS-1 (1:1,000; cat.no.ab5599), anti-phospho-Akt (1:5,000; cat. no. ab81283), anti-Akt (1:10,000; cat. no. ab179463), anti-ERK (1:1,000; cat. no. ab17942) and anti-phospho-ERK (1:1,000; cat. no. ab214362,) overnight at $4^{\circ} \mathrm{C}$. The blots were then incubated with HRP-labeled goat anti-rabbit IgG (1:500; cat.no. A0208; Beyotime Institute of Biotechnology) or HRP-labeled Goat Anti-Mouse IgG (1:500; cat.no. A0216; Beyotime Institute of Biotechnology) for $1 \mathrm{~h}$ at room temperature. The bands were visualized using enhanced chemiluminescence reagent (Beyotime Institute of Biotechnology). The western blot analysis results are representative of $\geq 3$ experiments.

RT-qPCR. MC3T3-E1 cell total RNA was extracted using TRIzol reagent (Beyotime Institute of Biotechnology) for $10 \mathrm{~min}$ at $4^{\circ} \mathrm{C}$ and quantified spectrophotometrically. Single-stranded cDNA was synthesized using SuperScript II Reverse Transcriptase (Takara Biomedical Technology Co., Ltd.) according to the manufacturer's instructions. SYBR-Green quantitative PCR Biomedical Technology Co., Ltd.) analysis was performed with an ABI PRISM Sequence Detection System (Applied Biosystems; Thermo Fisher Scientific, Inc.) and pre-validated primer sets (Qiagen $\mathrm{GmbH}$ ). Transcripts were amplified by 40 cycles of the following: $95^{\circ} \mathrm{C}$ for $30 \mathrm{sec}$ (denaturation), $60^{\circ} \mathrm{C}$ for $30 \mathrm{sec}$ (annealing) and $72^{\circ} \mathrm{C}$ for $30 \mathrm{sec}$ (extension). All samples were analyzed in triplicate. Threshold cycles were placed in the logarithmic portion of the amplification curve, and the results were normalized to GAPDH. The fold difference between two samples was determined by $2^{-\Delta \Delta \mathrm{Cq}}$ method (21). The primer sequences are presented in Table I.

Statistical analysis. Data are presented as the mean \pm SD. Statistical analysis was performed using one-way ANOVA followed by Tukey's test using GraphPad Prism version 5.0c (GraphPad Software, Inc.). $\mathrm{P}<0.05$ was considered to indicate a statistically significant difference.

\section{Results}

Effects of PAP on cell viability and proliferation. A previous study revealed that PAP could potentiate osteoblast differentiation and inhibit osteoclastogenesis at 5-40 mg/l (20). Another previous study found that PAP protected osteoblasts from inflammatory and oxidative injury at $25-100 \mathrm{mg} / 1$ (19). The present study performed an MTT assay to investigate whether PAP was cytotoxic to MC3T3-E1 cells. No cytotoxic effects were observed at $24 \mathrm{~h}$, even at the concentration $150 \mathrm{mg} / \mathrm{l} \mathrm{PAP}$ (Fig. 1A). Therefore, 25, 50 and $100 \mathrm{mg} / 1$ PAP were classified as low, middle and high concentrations, respectively.
Table I. Primer sequence.

\begin{tabular}{ll}
\hline Gene & \multicolumn{1}{c}{ Primer sequence $\left(5^{\prime} \rightarrow 3^{\prime}\right)$} \\
\hline GAPDH & F: AGAAGGTGGTGAAGCAGGCATC \\
& R: CGAAGGTGGAAGAGTGGGAGTTG \\
CoI & F: GAGGCATAAAGGGTCATCGTGG \\
& R: CATTAGGCGCAGGAAGGTCAGC \\
OPN & F: CCAAGCGTGGAAACACACAGCC \\
& R: GGCTTTGGAACTCGCCTGACTG \\
OCN & F: GGTGCAGACCTAGCAGACACCA \\
& R: AGGTAGCGCCGGAGTCTATTCA
\end{tabular}

CoI, collagen I; ALP, alkaline phosphatase; OPN, osteopontin; OCN, osteocalcin; F, forward; R, reverse.

The present study investigated the effects of PAP on cell proliferation. MC3T3-E1 osteoblastic cells were cultured in 96 -well plate and treated with various concentrations of PAP $(0$, 25,50 and $100 \mathrm{mg} / \mathrm{l}$ ) for 1-7 days. The present results suggested that when culture time was extended to 5 days, treatment with $50 \mathrm{mg} / \mathrm{l}$ PAP significantly increased the proliferation of MC3T3-E1 cells. Furthermore, the maximum cell proliferative ability observed was with $50 \mathrm{mg} / \mathrm{l}$ PAP on day 7 (Fig. 1B).

Effects of PAP on osteoblast differentiation and mineralization. The present study investigated the effects of PAP on osteoblastogenesis in MC3T3-E1 cells. The present ALP staining results (Fig. 1C) indicated that PAP increased osteoblast differentiation at day 7. This trend was identified in the later ALP activity analysis. PAP increased ALP activity in a dose-dependent manner, and ALP activity in the high concentration group $(100 \mathrm{mg} / \mathrm{l})$ was increased by almost 2 -3-fold (Fig. 1D). At day 14, PAP increased the cell staining density of Alizarin Red S (Fig. 1E), and subsequent quantitative analysis further indicated that PAP promoted osteoblast mineralization (Fig. 1F).

Effects of PAP on the expression levels of specific genes in MC3T3-E1 cells. The present study examined the expression levels of specific marker genes in osteoblasts, including collagen I (CoI), alkaline phosphatase (ALP), osteopontin (OPN) and osteocalcin (OCN) by RT-qPCR (21). Collagen I (CoI) is an early marker of the pre-osteoblast lineage, which progressively expresses alkaline phosphatase (ALP) during the maturation stage and then osteopontin (OPN) and osteocalcin (OCN) during the mineralization phase (22). The present results suggested that PAP increased the expression levels of the osteogenic-specific genes in a dose-dependent manner from day 3, with a steady increase until day 7 (Fig. 2). The present results suggested that PAP may influence the early stages of osteoblast differentiation and the late stage of mineralization.

PAP induces the activation of the insulin signaling pathway. The insulin signaling pathway plays a central role in osteoblast development (6). After 7 days of treatment, PAP increased the 
A

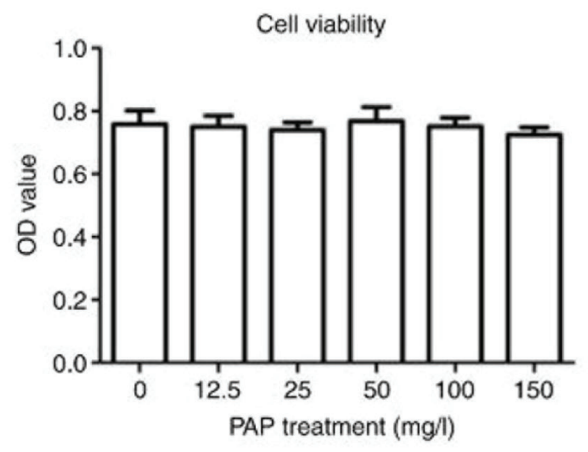

B

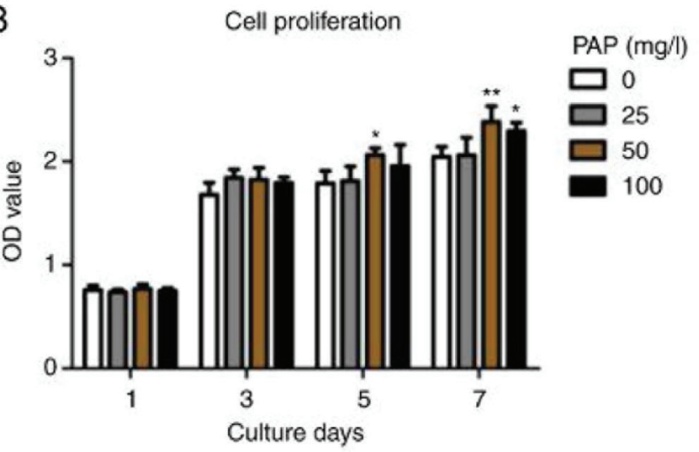

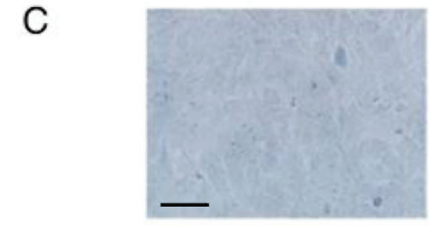

$\operatorname{PAP}(\mathrm{mg} /)$

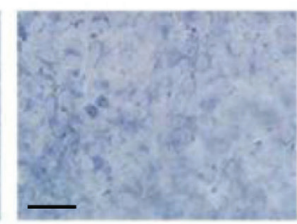

25

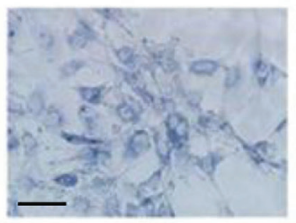

50

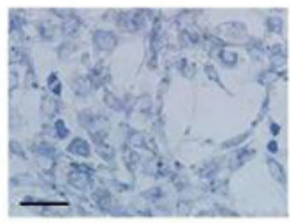

100

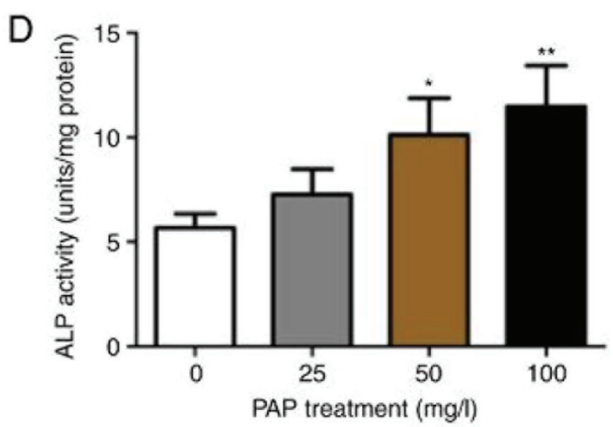

$E$

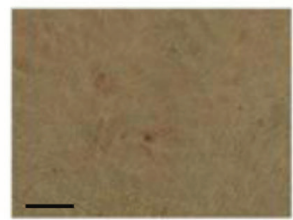

0

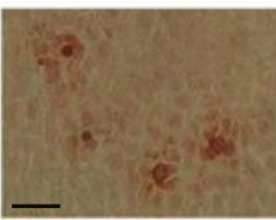

25

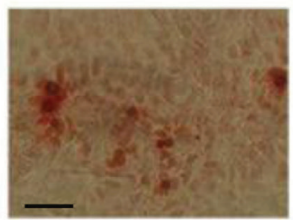

50

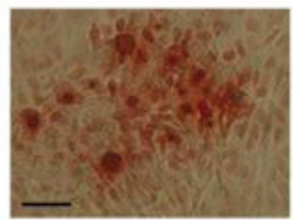

100

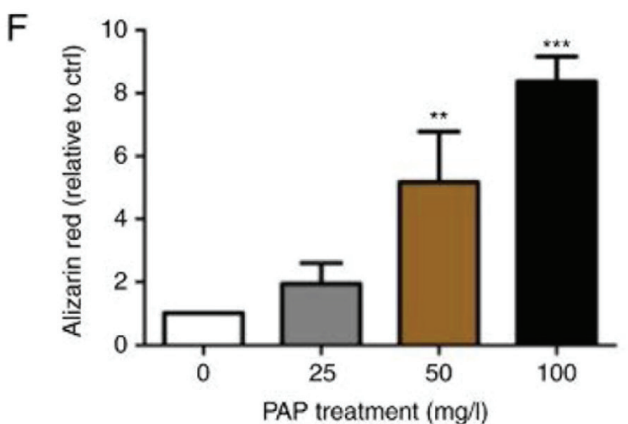

Figure 1. Effects of PAP on cell viability and osteogenic development in MC3T3-Elcells. (A) Cells were treated with the indicated concentrations of PAP for $24 \mathrm{~h}$, then cell viability was assessed using MTT assay. (B) Cells were treated with $0,25,50$ or $100 \mathrm{mg} / \mathrm{l}$ PAP for the specified days and assessed with the MTT assay. (C) ALP staining and (D) activity quantitative assay of MC3T3-E1 treated with different doses of PAP after 7 days. (E) Alizarin red staining and (F) quantification after 14 days. Scale bar, $20 \mu \mathrm{m}$. Data are presented as mean $\pm \mathrm{SD} .{ }^{*} \mathrm{P}<0.05,{ }^{* *} \mathrm{P}<0.01,{ }^{* * * *} \mathrm{P}<0.001$ vs. control group. PAP, pilose antler peptide; ALP, alkaline phosphatase; OD, optical density.

expression level of InsR in a dose-dependent manner (Fig. 3A). Treatment with $100 \mathrm{mg} / \mathrm{l}$ PAP significantly increased the expression level of IRS-1, and treatment with $50 \mathrm{mg} / \mathrm{l}$ PAP significantly increased the expression level of IRS-2. The present study investigated the role of the insulin signaling pathway in the induction of osteogenic differentiation by PAP by measuring the phosphorylated and total protein levels of InsR, IRS-1, Akt and ERK following treatment with 

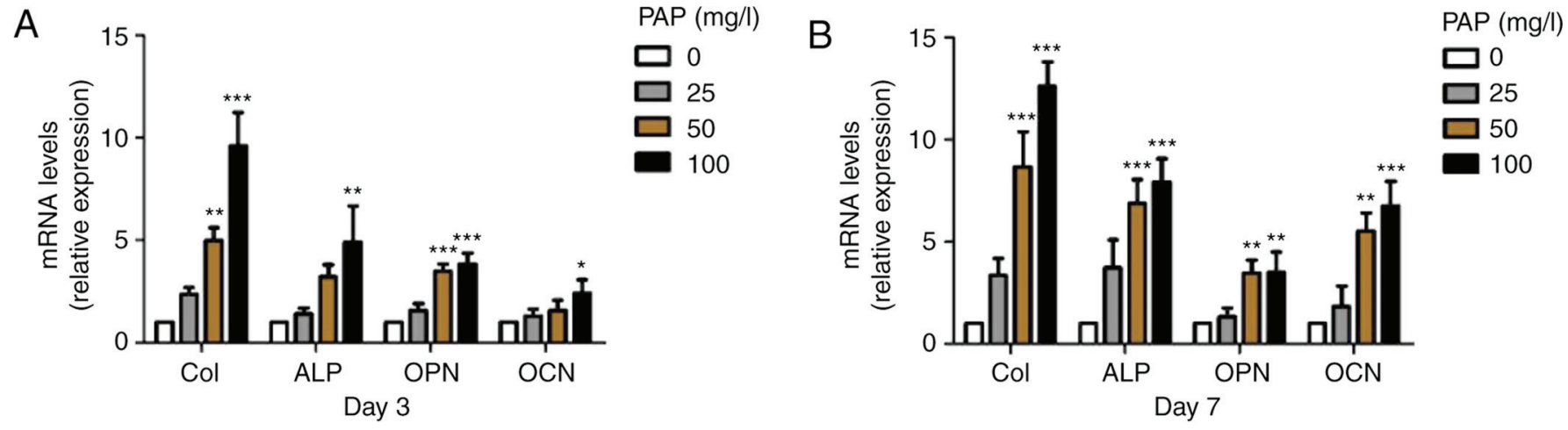

Figure 2. Effects of PAP on specific genes expression during osteoblast development by reverse transcription-quantitative PCR. (A) Cells were treated with the indicated concentrations of PAP for 3 days. (B) Cells were treated with the indicated concentrations of PAP for 7 days. Data are presented as mean \pm SD. ${ }^{*} \mathrm{P}<0.05,{ }^{* *} \mathrm{P}<0.01,{ }^{* * * *} \mathrm{P}<0.001$ vs. control group. PAP, pilose antler peptide; CoI, collagen I; ALP, alkaline phosphatase; OPN, osteopontin; OCN, osteocalcin.

A

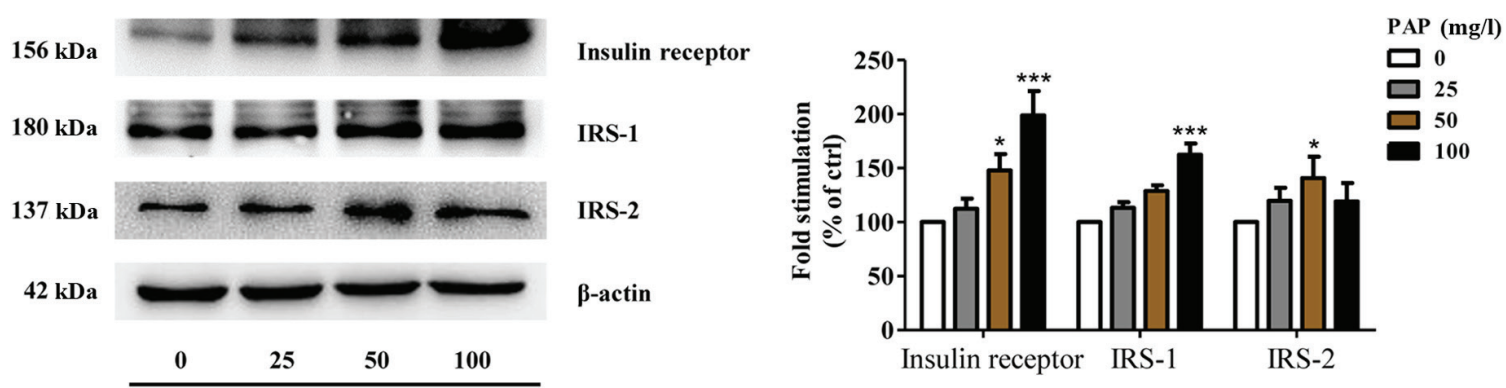

B

PAP (mg/)
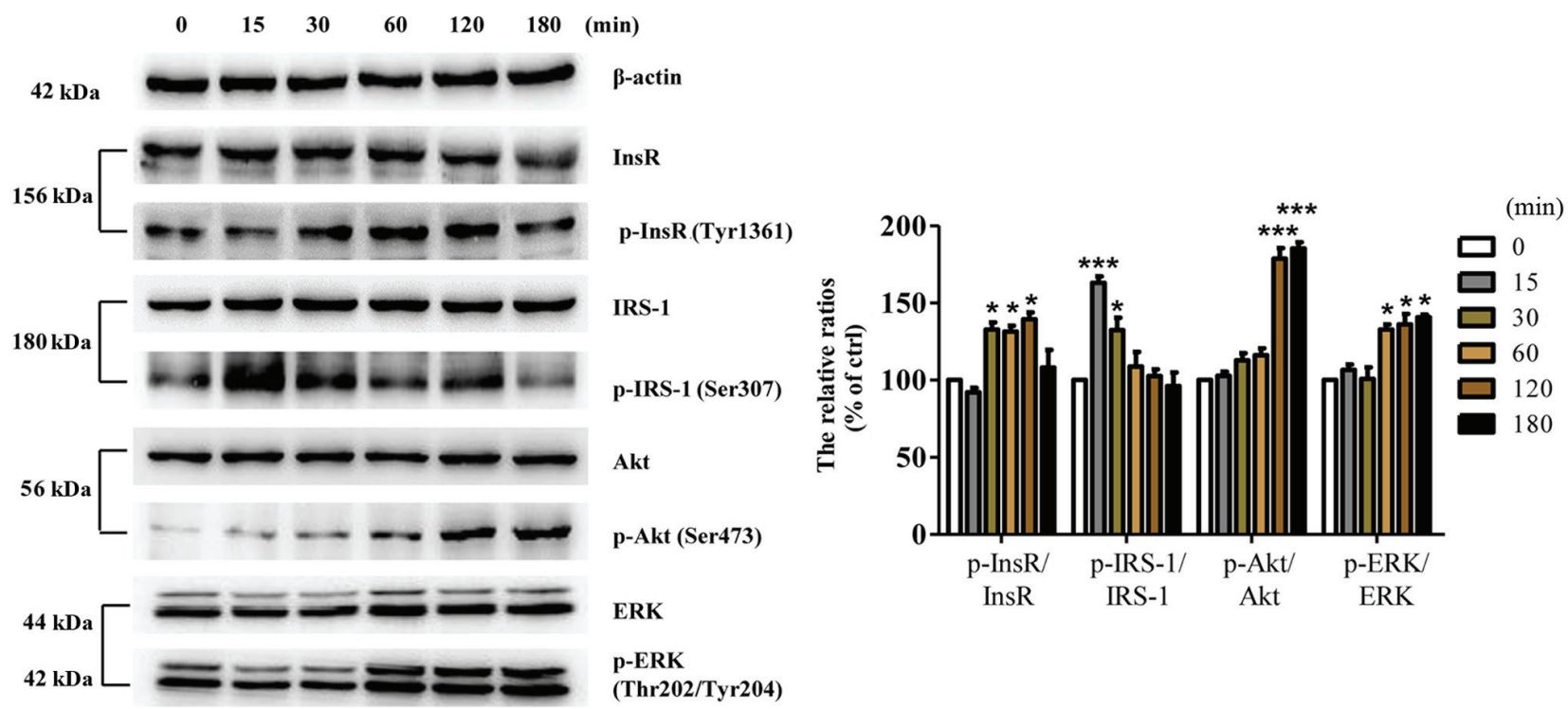

Figure 3. Effects of PAP on insulin signaling in MC3T3-E1 cells. (A) Western blot analysis of expression levels of insulin signaling pathway factors after treatment with the indicated concentrations of PAP for 7 days. (B) Western blotting and densitometric analysis of the phosphorylated and total InsR, IRS-1, Akt and ERK under $100 \mathrm{mg} / \mathrm{l}$ PAP treatment at 0, 15, 30, 60 and $120 \mathrm{~min}$. Data are presented as mean $\pm \mathrm{SD} .{ }^{*} \mathrm{P}<0.05,{ }^{* * *} \mathrm{P}<0.001$ vs. control group. PAP, pilose antler peptide; IRS, insulin receptor substrate; InsR, insulin receptor; t-, total; p-, phosphorylated; Ctrl, control.

$100 \mathrm{mg} / \mathrm{l}$ PAP for $0,15,30,60$ and $120 \mathrm{~min}$. Treatment with $100 \mathrm{mg} / \mathrm{l}$ PAP induced the phosphorylation of InsR, IRS-1, Akt and ERK (Fig. 3B). The phosphorylated InsR expression level was increased over the first 15 and $30 \mathrm{~min}$, while total
InsR expression level exhibited no significant change. PAP increased Akt phosphorylation at $30 \mathrm{~min}$, with peak activation being reached at $60 \mathrm{~min}$. IRS-1 and ERK were activated within $30 \mathrm{~min}$ and lasted until $120 \mathrm{~min}$. 
A
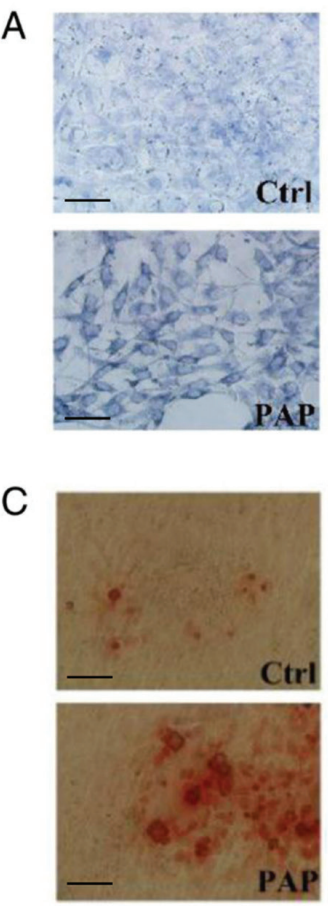
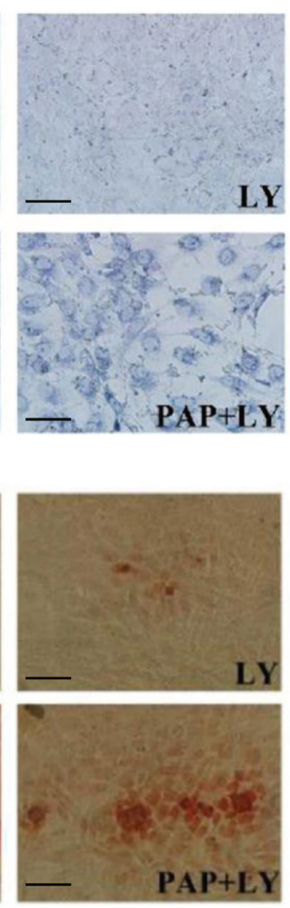
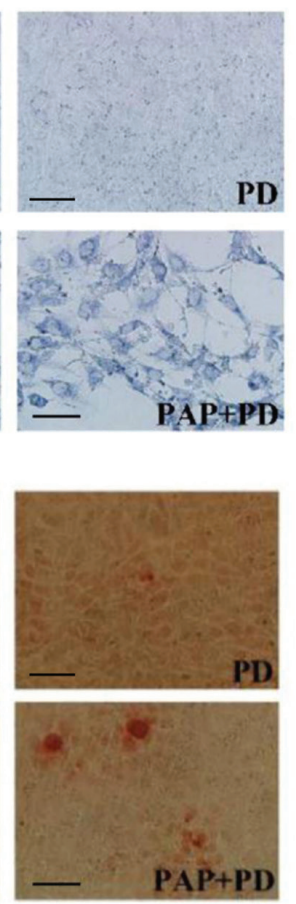

$\mathrm{B}$
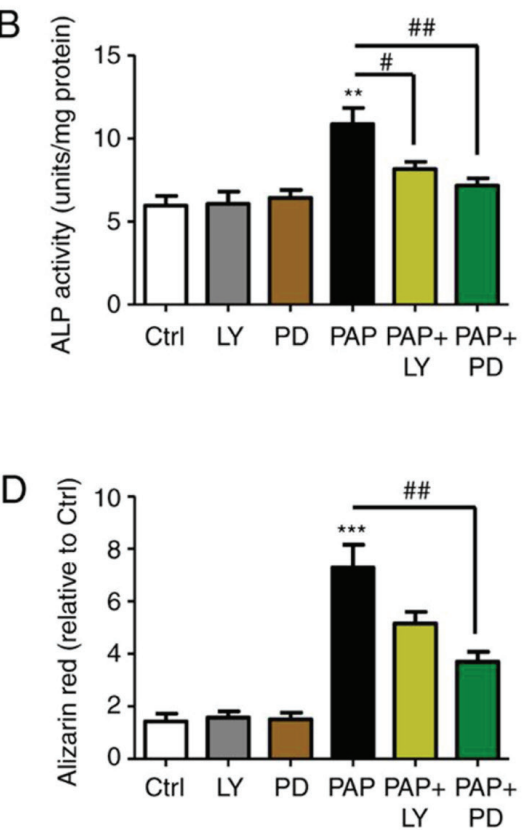

Figure 4. Effects of PI3K and ERK inhibitors on osteogenic development after PAP treatment. (A) ALP staining and (B) activity quantitative assay of 100 mg/1 PAP treated MC3T3-E1 with or without $10 \mu \mathrm{M} \mathrm{LY}$ or $20 \mu \mathrm{M}$ PD after 7 days. (C) Alizarin red staining and (D) quantification after 14 days. Scale bar, $20 \mu \mathrm{m}$. Data are presented as mean $\pm \mathrm{SD} .{ }^{* *} \mathrm{P}<0.01,{ }^{* * *} \mathrm{P}<0.001$ vs. control group. ${ }^{\#} \mathrm{P}<0.05,{ }^{\#} \mathrm{P}<0.01$ vs. PAP group. LY, LY294002; PD, PD98059; PAP, pilose antler peptide; Ctrl, control; ALP, alkaline phosphatase.

Validation of the regulatory effects of PAP on the insulin signaling pathway. There are two main downstream insulin signaling pathways, the PI3K/Akt pathway, which is mainly responsible for metabolic functions, and the MAPK pathway, which regulates the expression of certain genes and cooperates with the PI3K/Akt pathway to control cell growth and differentiation (12). The present western blotting results suggested that PAP can activate both the PI3K/Akt and the MAPK pathway. Therefore, PI3K (LY) and ERK (PD) inhibitors were used to investigate this mechanism. The present results from ALP staining (Fig. 4A) and activity assays (Fig. 4B) indicated that the inhibitors LY and PD reversed the effects of PAP on ALP activity after 7 days. After 14 days, PD inhibitor significantly inhibited PAP-induced osteoblast mineralization, while LY inhibitor had no significant effect (Fig. 4C and D). In addition, neither LY or PD in the absence of PAP showed any effect on osteoblast proliferation, differentiation and mineralization (Figs. 4 and S1). Therefore, the present results suggested that the MAPK pathway may be involved in the PAP-mediated osteoblast differentiation and mineralization, and that the PI3K/Akt pathway may at least in part be involved in this process.

\section{Discussion}

There is increasing evidence to indicate that diabetes mellitus, characterized by a lack of insulin production or sensitivity, is associated with reduced bone mineral density and increased fracture risk and delayed fracture healing (23-25). Insulin has been proposed as an anabolic agent in bone metabolism (5). Mice lacking insulin receptors in osteoblasts have been shown to develop postnatal osteopenia and an impairment of osteoblast proliferation and differentiation, and direct treatment with insulin has been shown to promote osteoblast proliferation, collagen synthesis and alkaline phosphatase production $(5,6)$. The molecular mechanism of insulin signaling in osteoblast was found to be related to the MAPK and PI3K pathway (7). Furthermore, recent studies found a positive loop between osteocalcin, an osteoblast-specific hormone and insulin (8). Bone, as an endocrine organ, can secrete osteocalcin to modulate glucose metabolism, and conversely, high glucose and insulin resistance downregulate osteocalcin gene expression and negatively affect osteoblast differentiation (26). Thus, the role of insulin signaling in regulating bone growth and metabolism has been revealed by a number of studies, and agents which can activate insulin signaling in osteoblasts can potentially be used in the treatment of diabetes-related osteoporosis and bone disease.

PAP, extracted from the pilose antler, is as well-known Chinese traditional medicine used to promote regeneration and fracture healing, and to strengthen sinews and bone (13). The present results suggested that PAP improved osteogenic proliferation, differentiation and mineralization, which was determined by the number and function of osteoblasts. At day 7 , the middle and high concentration PAP groups showed significantly increased cell proliferation, and induced ALP activity, particularly at the concentration of $100 \mathrm{mg} / \mathrm{l}$, and also promoted osteogenic mineralization at day 14 . CoI has an apparent effect on the biomechanical strength of bone tissue by providing the structural framework for inorganic molecule deposition (22). OPN, as an intermediate or relatively earlier marker of osteogenic differentiation, is associated with the maturation stage of osteoblasts during attachment, and matrix synthesis before mineralization (22). OCN is related to matrix deposition and mineralization as a late marker of osteogenic differentiation (22). The present results indicated that PAP increased the expression 
levels of osteogenic-specific genes in a dose-dependent manner from day 3 , with a steady increase until day 7 ; the present results were similar to those reported by Liu et al (20).

The present results suggested that PAP significantly increased the expression levels of InsR and IRS-1, but had a weak effect on the expression level of IRS-2 after 7 days of treatment. The biological effects of insulin signaling are mediated by the phosphorylation of insulin receptor itself and downstream substrates, such as IRS-1, Akt and ERK (12). The present results indicated that treatment with $100 \mathrm{mg} / \mathrm{l}$ PAP induced the phosphorylation of InsR at $15 \mathrm{~min}$ and that of IRS-1 at $30 \mathrm{~min}$. The PI3K/Akt and MAPK signaling pathways are involved in the induction of cell proliferation and differentiation by insulin; therefore, the present study investigated the activation of Akt and ERK in MC3T3-E1 cells following treatment with PAP. The present results identified that treatment with $100 \mathrm{mg} / \mathrm{l}$ PAP resulted in the activation of both Akt and ERK. Thus, the present results suggested that PAP may activate the insulin signaling pathway by promoting the phosphorylation of the insulin receptor and downstream substrates, such as IRS-1, Akt and ERK. Furthermore, the effects of PAP on ALP activity in osteoblasts after 7 days were inhibited by the ERK inhibitor PD, and partly by the PI3K inhibitor LY. In addition, bone nodule formation in the MC3T3-E1 cells stimulated with PAP after 14 days was attenuated by PD, but not by LY. The present results suggested that the effects of PAP on osteoblastogenesis via the modulation of insulin signaling in osteoblasts were mediated by the ERK pathway and at least partly by the PI3K/Akt pathway.

In conclusion, the present results indicated that PAP promoted osteoblast proliferation, differentiation and mineralization in vitro by manipulating the insulin signaling pathway. The MAPK and PI3K/Akt signaling pathways may be the mechanisms involved in the effects of PAP. The present results suggested that PAP may potentially be developed as an alternative therapy for bone diseases related to diabetes characterized by an impairment in insulin signaling. PAP has been widely used as traditional medicine in Asia, and has been demonstrated that have beneficial effects $(13,14)$. In the present study, all the experiments were carried out in vitro. Further studies are ongoing to investigate whether PAP can promote bone remodeling in an osteoporosis animal model.

\section{Acknowledgements}

Not applicable.

\section{Funding}

This work was supported by the Fund of Changzhou Sci\&Tech Program (grant no. CJ20180007).

\section{Availability of data and materials}

The datasets used and/or analyzed during the current study are available from the corresponding author on reasonable request.

\section{Authors' contributions}

CJY conceived the project, designed and performed the experiments, analyzed the data and wrote the manuscript. WQ and
JW performed the experiments and analyzed the data. CXY and SJ performed the experiments and revised the manuscript. JL conceived the project, designed the experiments and revised the manuscript. All authors read and approved the final manuscript.

\section{Ethics approval and consent to participate}

Not applicable.

\section{Patient consent for publication}

Not applicable.

\section{Competing interests}

The authors declare that they have no competing interests.

\section{References}

1. Johnell $\mathrm{O}$ and Kanis JA: An estimate of the worldwide prevalence and disability associated with osteoporotic fractures. Osteoporos Int 17: 1726-1733, 2006

2. Editorial Board of Osteoporosis prevention and treatment: (China White Paper). Chin J Health Manage 3: 148-154, 2009 (In Chinese).

3. Wang Y, Tao Y, Hyman ME, Li J and Chen Y: Osteoporosis in China. Osteoporos Int 20: 1651-1662, 2009.

4. Zaidi M: Skeletal remodeling in health and disease. Nat Med 13: 791-801, 2007.

5. Ferron M, Wei J, Yoshizawa T, Fattore AD, DePinho RA, Teti A, Ducy P and Karsenty G: Insulin signaling in osteoblasts integrates bone remodeling and energy metabolism. Cell 142: 296-308, 2010

6. Fulzele K, Riddle RC, DiGirolamo DJ, Cao X, Wan C, Chen D, Faugere MC, Aja S, Hussain MA, Bruning JC and Clemens TL: Insulin receptor signaling in osteoblasts regulates postnatal bone acquisition and body composition. Cell 142: 309-319, 2010.

7. Yang J, Zhang X, Wang W and Liu J: Insulin stimualtes osteoblast proliferation and differentiation through ERK and PI3K in MG-63 cells. Cell Biochem Funct 28: 334-341, 2010.

8. Zhang W, Shen X, Wan C, Zhao Q, Zhang L, Zhou Q and Deng L: Effects of insulin and insulin-like growth factor 1 on osteoblast proliferation and differentiation: Differential signaling via Akt and ERK. Cell Biochem Funct 30: 297-302, 2012.

9. Oqata N, Chikazu D, Kubota N, Terauchi Y, Tobe K, Azuma Y, Ohta T, Kadowaki T, Nakamura K and Kawaguchi H: Insulin receptor substrate-1 in osteoblast is indispensable for maintaining bone turnover. J Clin Invest 105: 935-943, 2000

10. Akune T, Oqata N, Hoshi K, Kubota N, Terauchi Y, Tobe K, Takagi H, Azuma Y, Kadowaki T, Nakamura K and Kawaguchi H: Insulin receptor substrate-2 maintains predominance of anabolic function over catabolic function of osteoblasts. J Cell Biol 159: 147-156, 2002.

11. Huang C, Thirone AC, Huang $X$ and Klip A: Differential contribution of insulin receptor substrates 1 versus 2 to insulin signaling and glucose uptake in L6 myotubes. J Biol Chem 280: 19426-19435, 2005.

12. Taniquchi CM, Emanuelli B and Kahn CR: Critical nodes in signaling pathways: Insights into insulin action. Nat Rev Mol Cell Biol 7: 85-96, 2006.

13. Zhang ZQ, Zhang Y, Wang BX, Zhou HO, Wang Y and Zhang H: Purification and partial characterization of anti-inflammatory peptide from pilose antler of Cervus Nippon Temminck. Yao Xue Xue Bao 27: 321-324, 1992.

14. Zhang ZQ, Wang Y, Zhang $\mathrm{H}$, Zhang $\mathrm{W}$, Zhang $\mathrm{Y}$ and Wang BX: Anti-inflammatory effects of pilose antler peptide. Zhongguo Yao Li Xue Bao 15: 282-284, 1994 (In Chinese).

15. Wu T, Yang L, Chen Y, Ni Y, Jiang J, Zhang W, Zhou Q, Zheng X, Wang Q, Fu Z and Li H: Pilose antler polypeptides ameliorates hypoxic-ischemic encephalopathy by activated neurotrophic factors and SDF1/CXCR4 axis in rats. Acta Biochim Biophys Sin (Shanghai) 50: 254-262, 2018. 
16. Bai L, Shi W, Liu J, Zhao X, Zhang Y, Zhou Z, Hou W and Chang T: Protective effect of pilose antler peptide on cerebral ischemia/reperfusion (I/R) injury througe Nrf-2/OH-1/NF- $\mathrm{B}$ pathway. Int J Biol Macromol 102: 741-748, 2017.

17. Ma C, Long $\mathrm{H}$, Yang $\mathrm{C}$, Cai $\mathrm{W}$, Zhang $\mathrm{T}$ and Zhao $\mathrm{W}$ : Anti-inflammatory role of pilose antler peptide in LPS-induced lung injury. Inflammation 40: 904-912, 2017.

18. Chunhua M and Hongyan L: Protective effect of pilose antler peptide on carbon tetrachloride-induced hepatotoxicity in mice. Int J Biol Macromol 99: 648-654, 2017.

19. Chunhui Y, Wenjun C, Hui W, Liquan S, Changwei Z, Tianzhu Z and Wenhai Z: Pilose antler peptide protects osteoblasts from inflammatory and oxidative injury through EGF/EGFR signaling. Int J Biol Macromol 99: 15-20, 2017.

20. Liu G, Ma C, Wang P, Zhang P, Qu X, Liu S, Zhai Z, Yu D, Gao J, Liang J, et al: Pilose antler peptide potentiates osteoblast differentiation and inhibits osteoclastogenesis via manipulating the NF- $\mathrm{B}$ pathway. Biochem Biophys Res Commun 491: 388-395, 2017.

21. Livak KJ and Schmittgen TD: Analysis of relative gene expression data using real-time quantitative PCR and the 2(-Delta Delta C(T)) method. Methods 25: 402-408, 2001.
22. Song L, Zhao J, Zhang X, Li H and Zhou Y: Icariin induces osteoblast proliferation, differentiation and mineralization through estrogen receptor-mediated ERK and JNK signal activation. Eur J Pharmacol 714: 15-22, 2013.

23. Starup-Linde J, Frost M, Vesterqaard P and Abrahamsen B: Epidemiology of fractures in diabetes. Clacif Tissue Int 100: 109-121, 2017.

24. Kemink SA, Hermus AR, Swinkels LM, Lutterman JA and Smals AG: Osteopenia in insulin-dependent diabetes mellitus; prevalence and aspects of pathophysiology. J Endocrinol Invest 23: 295-303, 2000

25. Duarte VM,Ramos AM,Rezende LA,Macedo UB, Brandão-Neto J, Almeida MG and Rezende AA: Osteopenia: A bone disorder associated with diabetes mellitus. J Bone Miner Metab 23: 58-68, 2005.

26. Bilotta FL, Arcidiacono B, Messineo S, Greco M, Chiefari E, Britti D, Nakanishi T, Foti DP and Brunetti A: Insulin and osteocaclin: Further evidence for a mutual cross-talk. Endocrine 59: 622-632, 2018

(i) (9) This work is licensed under a Creative Commons

cc) $\mathrm{EY}$ NG ND Attribution-NonCommercial-NoDerivatives 4.0 International (CC BY-NC-ND 4.0) License. 